\title{
OXIDAÇÃO DE PROTEÍNAS POR OXIGÊNIO SINGLETE: MECANISMOS DE DANO, ESTRATÉGIAS PARA DETECÇÃO E IMPLICAÇÕES BIOLÓGICAS
}

Graziella E. Ronsein, Sayuri Miyamoto, Etelvino Bechara e Paolo Di Mascio*

Departamento de Bioquímica, Instituto de Química, Universidade de São Paulo, Av. Prof. Lineu Prestes, 748, 05508-900 São Paulo - SP, Brasil

\section{Glaucia R. Martinez}

Departamento de Bioquímica e Biologia Molecular, Setor de Ciências Biológicas, Universidade Federal do Paraná, Centro Politécnico, CP 19046, 81531-990, Curitiba - PR, Brasil

Recebido em 4/4/05; aceito em 26/7/05; publicado na web em 16/2/06

\begin{abstract}
SINGLET OXYGEN-MEDIATED PROTEIN OXIDATION: DAMAGE MECHANISMS, DETECTION TECHNIQUES AND BIOLOGICAL IMPLICATIONS. Proteins are potential targets for singlet molecular oxygen $\left({ }^{1} \mathrm{O}_{2}\right)$ oxidation. Damages occur only at tryptophan, tyrosine, histidine, methionine, and cysteine residues at physiological $\mathrm{pH}$, generating oxidized compounds such as hydroperoxides. Therefore, it is important to understand the mechanisms by which ${ }^{1} \mathrm{O}_{2}$, hydroperoxides and other oxidized products can trigger further damage. The improvement and development of new tools, such as clean sources of ${ }^{1} \mathrm{O}_{2}$ and isotopic labeling approaches in association with HPLC/mass spectrometry detection will allow one to elucidate mechanistic features involving ${ }^{1} \mathrm{O}_{2}$ mediated protein oxidation.
\end{abstract}

Keywords: singlet oxygen; protein oxidation; protein peroxide.

\section{INTRODUÇÃ̃O}

\section{Oxigênio singlete}

O oxigênio molecular, no estado fundamental, possui dois elétrons com spins paralelos ocupando dois orbitais $\pi$ de mesma energia, chamados de degenerados, caracterizando, portanto, um estado triplete $\left({ }^{3} \sum_{\mathrm{g}}^{-}\right)$. Conseqüentemente, a redução direta do oxigênio por dois elétrons é proibida pela regra de conservação do spin. Uma forma mais reativa do oxigênio, conhecida como oxigênio singlete, pode ser gerada por um acréscimo de energia. Nela, a restrição da regra de conservação do spin é removida. Sendo assim, o oxigênio singlete é muito mais oxidante que o oxigênio molecular no seu estado fundamental. Existem dois estados singlete do oxigênio: o primeiro estado excitado, ${ }^{1} \Delta_{\mathrm{g}}$, tem dois elétrons com spins opostos no mesmo orbital, possui uma energia de $22,5 \mathrm{kcal}$ acima do estado fundamental e tempo de meia vida em solvente aquoso de aproximadamente $10^{-6} \mathrm{~s}$; o segundo estado excitado, ${ }^{1} \sum_{\mathrm{g}}$, tem um elétron em cada orbital $\pi$ degenerado, com spins opostos, e possui uma energia de $37,5 \mathrm{kcal}$ acima do estado fundamental. O estado ${ }^{1} \Sigma_{\mathrm{g}}$ - tem um tempo de vida muito curto $\left(10^{-11} \mathrm{~s}\right)$ em meio aquoso, sendo rapidamente desativado para o estado ${ }^{1} \Delta_{\mathrm{g}}$. Portanto, apenas o primeiro estado apresenta interesse em sistemas biológicos e será denotado por ${ }^{1} \mathrm{O}_{2}$ (Tabela 1$)^{1}$.

Por se tratar de uma espécie eletronicamente excitada, o ${ }^{1} \mathrm{O}_{2}$ decai para o estado fundamental emitindo luz. A investigação espectroscópica da luminescência vermelha que acompanha a decomposição de peróxido de hidrogênio $\left(\mathrm{H}_{2} \mathrm{O}_{2}\right)$ na presença de hipoclorito $\left(\mathrm{OCl}^{-}\right)$(Equação 1), realizada por Khan e Kasha², revelou a existência de duas bandas de emissão centradas em 634 e 703 $\mathrm{nm}$, atribuídas ao decaimento para o estado fundamental do ${ }^{1} \mathrm{O}_{2}$ gerado na reação.

*e-mail: pdmascio@iq.usp.br
Tabela 1. Distribuição eletrônica nos orbitais moleculares $\left(\pi^{*}\right)$ do oxigênio no estado excitado singlete $\left({ }^{1} \Sigma_{\mathrm{g}}+,{ }^{1} \Delta_{\mathrm{g}}\right)$ e no estado fundamental triplete $\left({ }^{3} \sum_{\mathrm{g}}^{-}\right)$

\begin{tabular}{|c|c|c|c|}
\hline Estado & Orbitais $\pi^{*}$ & $\begin{array}{c}\text { Energia } \\
(\mathrm{kcal} / \mathrm{mol})\end{array}$ & $\begin{array}{l}\text { Tempo de } \\
\text { vida (s) }\end{array}$ \\
\hline${ }^{1} \sum_{\mathrm{g}}^{+}$ & $\uparrow \quad \downarrow$ & 37,5 & $10^{-11}$ \\
\hline${ }^{1} \Delta_{\mathrm{g}}$ & $\hat{t}$ & 22,5 & $10^{-6}$ \\
\hline${ }^{3} \sum_{\mathrm{g}}$ & $\uparrow \uparrow$ & & \\
\hline
\end{tabular}

$\mathrm{OCl}^{-}+\mathrm{H}_{2} \mathrm{O}_{2} \rightarrow \mathrm{Cl}^{-}+\mathrm{H}_{2} \mathrm{O}+{ }^{1} \mathrm{O}_{2}$

Atualmente, está bem estabelecido que essas bandas correspondem à transição simultânea de duas moléculas de ${ }^{1} \mathrm{O}_{2}$ ao estado fundamental triplete, também conhecida como emissão bimolecular (Equação 2). Esta emissão pode ser monitorada por meio de uma fotomultiplicadora sensível à região do vermelho do espectro visível, termoeletricamente resfriada, conectada a um sistema discriminador e amplificador ${ }^{3}$.

Além do decaimento bimolecular do ${ }^{1} \mathrm{O}_{2}$, também existe a transição monomolecular do ${ }^{1} \mathrm{O}_{2}$, que ocorre na região do infravermelho próximo (Equação 3). A luminescência desta transição pode ser detectada por um espectrômetro acoplado a um fotodetector cons-

Emissão bimolecular:

$\mathrm{O}_{2}\left({ }^{1} \Delta_{\mathrm{g}}\right)+\mathrm{O}_{2}\left({ }^{1} \Delta_{\mathrm{g}}\right) \rightarrow 2 \mathrm{O}_{2}\left({ }^{3} \Sigma_{\mathrm{g}}^{-}\right)+\mathrm{h} v(\lambda=634$ e $703 \mathrm{~nm})$

Emissão monomolecular:

$\mathrm{O}_{2}\left({ }^{1} \Delta_{\mathrm{g}}\right) \rightarrow \mathrm{O}_{2}\left({ }^{3} \sum_{\mathrm{g}}^{-}\right)+\mathrm{hv} \quad(\lambda=1270 \mathrm{~nm})$ 
tituído de um fotodiodo de germânio resfriado com nitrogênio líquido ${ }^{4}$. Recentemente, nosso laboratório desenvolveu um sistema de detecção composto por uma fotomultiplicadora sensível na região do infravermelho (800 a $1700 \mathrm{~nm}$ ), que é refrigerada a $-80{ }^{\circ} \mathrm{C}$ por meio de nitrogênio líquido. Este sistema está conectado a uma fonte de alta tensão e a um monocromador capaz de varrer as regiões do ultravioleta, visível e infravermelho. Para o infravermelho, utiliza-se uma grade capaz de varrer entre 800 e $2700 \mathrm{~nm}$ (Figura 1). A intensidade da emissão monomolecular é diretamente proporcional à concentração do ${ }^{1} \mathrm{O}_{2} \mathrm{e}$, portanto, fornece uma medida direta da quantidade produzida ${ }^{5}$.

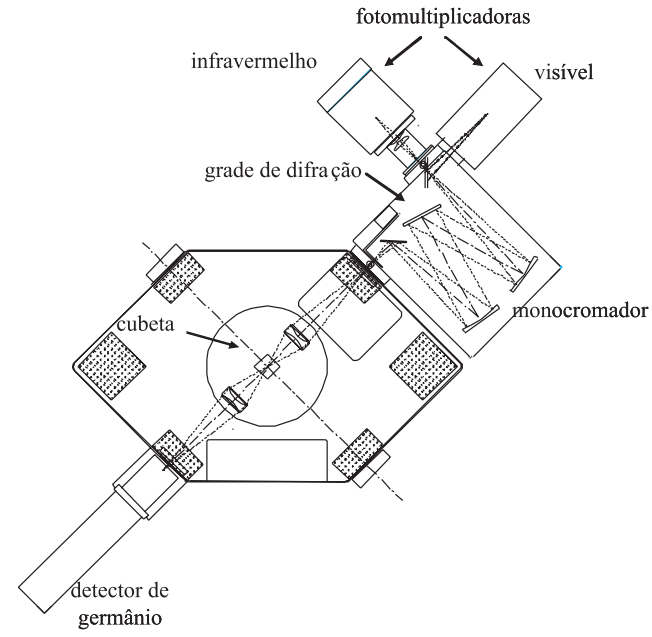

Figura 1. Equipamento de detecção utilizado para medidas de emissão de luz no infravermelho e no visível. O equipamento contém uma câmara para amostra e dois sistemas de detecção: o detector de germânio e duas fotomultiplicadoras acopladas a um monocromador

\section{Fontes de ${ }^{1} \mathrm{O}_{2}$}

Em laboratório, o ${ }^{1} \mathrm{O}_{2}$ é geralmente gerado por reações de fotossensibilização. Nestas reações, são utilizadas moléculas conhecidas como fotossensibilizadores (tais como azul de metileno e rosa bengala) ${ }^{1}$. Quando estes fotossensibilizadores são irradiados com luz ultravioleta ou visível em determinados comprimentos de onda, absorvem energia e passam a um estado excitado singlete $\left({ }^{1} S^{*}\right)$. Este estado ${ }^{1} S^{*}$ pode decair para o estado fundamental singlete $\left({ }^{\circ} \mathrm{S}\right)$ com emissão de fluorescência, ou cruzar para um estado triplete excitado $\left({ }^{3} \mathrm{~S}^{*}\right)$ por inversão espontânea do spin do elétron excitado. Uma vez formado o ${ }^{3} \mathrm{~S}^{*}$, esta espécie pode participar em várias reações: pode decair ao estado ${ }^{0} \mathrm{~S}$ com emissão de fosforescência, ou reagir por mecanismos fotoquímicos do tipo I ou II. Na reação do tipo I, o ${ }^{3} \mathrm{~S}^{*}$ pode reagir com um substrato orgânico ou uma segunda molécula fotossensibilizadora, por transferência de elétrons ou hidrogênio. No tipo II, o fotossensibilizador ${ }^{3} \mathrm{~S}^{*}$ pode transferir energia para o oxigênio molecular, gerando ${ }^{0} \mathrm{~S}$ e ${ }^{1} \mathrm{O}_{2}$. Estes processos podem ocorrer simultaneamente e a importância de cada um depende da molécula alvo, da eficiência da transferência de energia do sensibilizador para o $\mathrm{O}_{2}$, do solvente e da concentração de $\mathrm{O}_{2}^{6-8}$ (Figura 2).

$\mathrm{O}^{1} \mathrm{O}_{2}$ pode ainda ser formado na termodecomposição de dioxetanos ${ }^{9}$ ou endoperóxidos de compostos policíclicos aromáti$\cos ^{10,11}$, na reação de $\mathrm{H}_{2} \mathrm{O}_{2}$ com $\mathrm{OCl}^{-}$ou peroxinitrito $\left(\mathrm{ONOO}^{-}\right)^{12-14}$ (Figura 3).

A geração de ${ }^{1} \mathrm{O}_{2}$ também tem sido evidenciada em meio biológico por reações que envolvem enzimas como as peroxidases, tais como lactoperoxidase ${ }^{15}$, mieloperoxidase ${ }^{16,17}$, cloroperoxidase $^{18}$

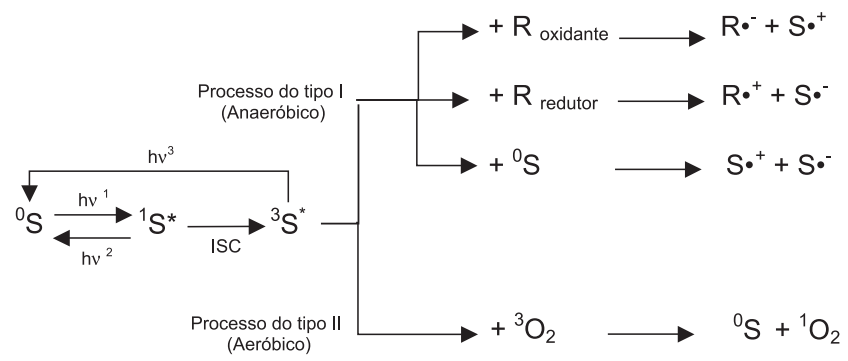

Figura 2. Representação esquemática dos mecanismos fotoquímicos do tipo I e do tipo II. Abreviaturas: $h v^{1}$ : radiação incidente; $h v^{2}$ : emissão de fluorescência; $h v^{3}$ : emissão de fosforescência; ${ }^{0} \mathrm{~S}$ : fotossensibilizador no estado fundamental; ${ }^{1} S^{*}$ : fotossensibilizador no estado singlete excitado; ${ }^{3} S^{*}$ : fotossensibilizador no estado triplete excitado; $S^{*}$ : radical ânion do fotossensibilizador; $S^{*+}$ : radical cátion do fotossensibilizador; $R$ : substrato orgânico; $R^{*}$ : radical ânion do substrato orgânico; $R^{*+}$ : radical cátion do substrato orgânico; ISC: cruzamento intersistemas

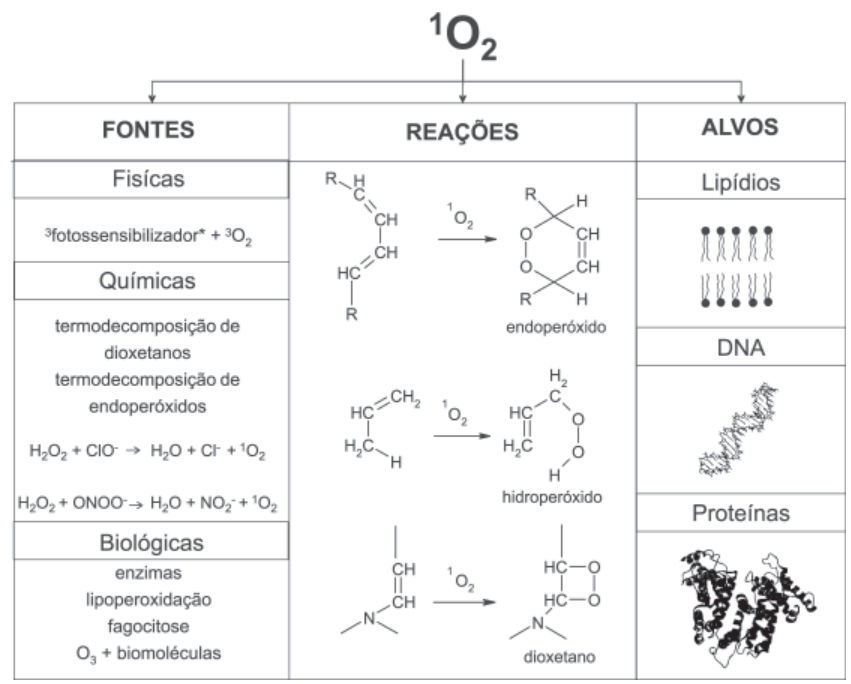

Figura 3. Fontes, reações e alvos do ${ }^{l} \mathrm{O}_{2}$

e peroxidase de raiz forte ${ }^{19}$. Também foram relatadas evidências da geração de ${ }^{1} \mathrm{O}_{2}$ na fagocitose ${ }^{20}$, na reação de ozônio $\left(\mathrm{O}_{3}\right)$ com biomoléculas $^{21}$ e no processo de lipoperoxidação ${ }^{22-24}$ (Figura 3). A formação de ${ }^{1} \mathrm{O}_{2}$ na lipoperoxidação ocorre principalmente por meio do mecanismo discutido por Russel1 ${ }^{22}$, no qual radicais peroxila interagem entre si, gerando um tetraóxido intermediário que se decompõe gerando como produtos um álcool, uma cetona e ${ }^{1} \mathrm{O}_{2}$.

\section{Alvos biológicos do ${ }^{1} \mathrm{O}_{2}$}

$\mathrm{O}^{1} \mathrm{O}_{2}$ pode interagir com outras moléculas de duas maneiras: através de reações químicas ou transferindo sua energia de excitação para estas moléculas e retornando ao estado fundamental. $\mathrm{O}$ último processo é conhecido como supressão física do ${ }^{1} \mathrm{O}_{2}$ e pode ser realizado por carotenóides, bilirrubina, tocoferóis, fenóis e azida ${ }^{1}$.

Algumas reações químicas do ${ }^{1} \mathrm{O}_{2}$ podem ser destacadas: adição a dienos conjugados (cicloadição do tipo Diels-Alder, $2+4$ ) geralmente resultando na formação de endoperóxidos ${ }^{25}$; adição 1,3 a uma dupla ligação, formando "ene" hidroperóxidos ${ }^{26}$ e, com alcenos substituídos por grupos contendo átomos de nitrogênio ou enxofre, formando 1,2-dioxetanos ${ }^{27}$ (Figura 3). $\mathrm{O}^{1} \mathrm{O}_{2}$ pode ainda reagir com compostos fenólicos para formar hidroperoxidienonas ${ }^{28}$ e com sulfetos, formando sulfóxidos ${ }^{29}$. Muitos estudos in vitro têm demonstrado que o ${ }^{1} \mathrm{O}_{2}$ oxida biomoléculas incluindo lipídios, pro- 
teínas, aminoácidos, ácidos nucléicos, carboidratos e tióis através dos mecanismos acima citados. Cabe ressaltar, entretanto, que as proteínas estão presentes em altas concentrações nos sistemas biológicos e as cadeias laterais de seus aminoácidos possuem constantes elevadas de desativação total do ${ }^{1} \mathrm{O}_{2}$ (constante total de desativação, $\left.\mathrm{k}_{\mathrm{t}}, \sim 10^{7} \mathrm{M}^{-1} \mathrm{~s}^{-1}\right)^{30-32}$, quando comparadas a outras biomoléculas, tais como, lipídios $\left(\mathrm{k}_{\mathrm{t}}, \sim 10^{4} \mathrm{M}^{-1} \mathrm{~s}^{-1}\right)^{33} \mathrm{e}$ bases do DNA $\left(\mathrm{k}_{\mathrm{t}}, \sim 10^{4}-10^{6} \mathrm{M}^{-1} \mathrm{~s}^{-1}\right)^{34}$ (Tabela 2). Desta forma, pode-se esperar que as proteínas sejam alvos importantes para $\mathrm{O}^{1} \mathrm{O}_{2}{ }^{35}$.

Tabela 2. Constantes de desativação total $\left(\mathrm{k}_{\mathrm{t}}\right)$ do ${ }^{1} \mathrm{O}_{2}$ com algumas biomoléculas.

\begin{tabular}{lcc}
\hline Composto & $\mathrm{k}_{\mathrm{t}}\left(10^{6} \mathrm{M}^{-1} \mathrm{~s}^{-1}\right)$ & Ref. \\
\hline Triptofano & $32^{\mathrm{a}}$ & 30 \\
Histidina & $46^{\mathrm{b}}$ & 30 \\
Tirosina & $2-5^{\mathrm{a}}$ & 30 \\
Cisteína & $50^{\mathrm{a}}$ & 30 \\
Meionina & $13^{\mathrm{a}}$ & 30 \\
Ácido linoleico & $0,073^{\mathrm{b}}$ & 33 \\
Colesterol & $0,057^{\mathrm{b}}$ & 33 \\
Guanina & $3,0^{\mathrm{c}}$ & 34 \\
Citosina & $0,058^{\mathrm{c}}$ & 34 \\
\hline
\end{tabular}

a em água deuterada:etanol (1:1); ${ }^{\mathrm{b}}$ em benzeno deuterado; ${ }^{\mathrm{c}}$ em 1,1,2-triclorotrifluoretano.

\section{Aminoácidos e peptídeos como alvos para o ${ }^{1} \mathrm{O}_{2}$}

A maioria das interações do ${ }^{1} \mathrm{O}_{2}$ com aminoácidos, peptídeos e proteínas ocorre via rotas químicas e não através de supressão física, sendo que ambos os mecanismos concorrem significativamente somente no caso do triptofano ${ }^{36}$. As constantes para a reação química do ${ }^{1} \mathrm{O}_{2}$ com as cadeias laterais dos aminoácidos livres variam dramaticamente, resultando em um dano seletivo a certos resíduos. Dos aminoácidos comuns, apenas triptofano, histidina, tirosina, metionina, cisteína e cistina reagem significativamente com ${ }^{1} \mathrm{O}_{2}$ em pH fisiológico ${ }^{31,32}$.

\section{Reação com resíduos de triptofano}

A reação do ${ }^{1} \mathrm{O}_{2}$ com o triptofano produz um hidroperoxipirroloindol isolável, entretanto, o precursor deste composto ainda não foi identificado ${ }^{37}$. Postula-se que ele seja um dioxetano formado com a dupla ligação dos carbonos $\mathrm{C}_{2}-\mathrm{C}_{3}$ do anel indólico, ou ainda um hidroperóxido no carbono $\mathrm{C}_{3}$. A decomposição subseqüente destes intermediários via quebra da ligação entre os carbonos $\mathrm{C}_{2}-\mathrm{C}_{3}$ origina $\mathrm{N}$-formilquinurenina, $3 \alpha$-hidroperoxipirroloindol e 3 $\alpha$-hidroxipirroloindol. A decomposição do $3 \alpha$-hidroperoxipirroloindol e do $3 \alpha$-hidroxipirroloindol também gera $N$-formilquinurenina $^{38-40}$ (Esquema 1). Os produtos finais da oxidação - $N$ formilquinurenina e quinurenina - têm sido detectados tanto em resíduos livres do aminoácido quanto em resíduos de triptofano de peptídios e proteínas ${ }^{35}$. Cabe ressaltar que a oxidação do triptofano em dipeptídios leva preferencialmente à formação do hidroperoxipirroloindol e seu álcool correspondente e, em menores quantidades, quinurenina ${ }^{41}$.

\section{Reação com resíduos de tirosina}

Com o aminoácido livre, demonstrou-se a formação de $3 \alpha$ hidroxi-6-oxo-2,3,3 $\alpha, 6,7,7 \alpha$-hexaidro-1H-indol-2-ácido carboxilíco (HOHICA) na reação com o ${ }^{1} \mathrm{O}_{2}$. Acredita-se que este produto seja gerado via um intermediário endoperóxido instável, pela cicloadição $[4+2]$ do ${ }^{1} \mathrm{O}_{2}$. A subseqüente abertura do anel forma

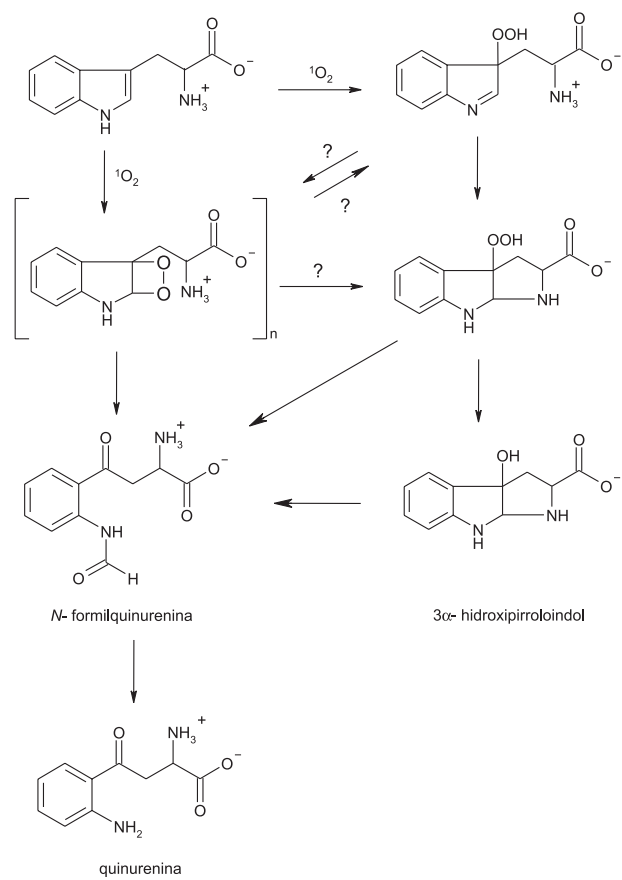

Esquema 1. Proposta do mecanismo de reação do ${ }^{l} \mathrm{O}_{2}$ com resíduos de triptofano. Adaptado das refs. 37-39

um hidroperóxido no carbono $\mathrm{C}_{1}$, o qual via uma reação do tipo de Michael sofre ciclização, resultando em um peróxido cíclico. Tem sido proposto que a decomposição do endoperóxido também gera 3,4-diidroxifenilalanina (DOPA) $)^{42-44}$ (Esquema 2).

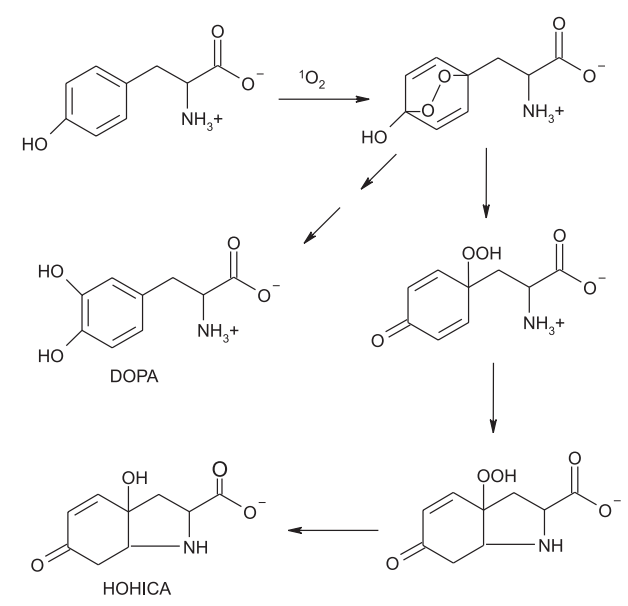

Esquema 2. Proposta do mecanismo de reação do ${ }^{1} \mathrm{O}_{2}$ com resíduos de

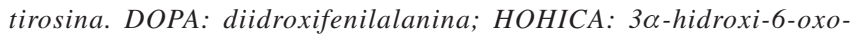

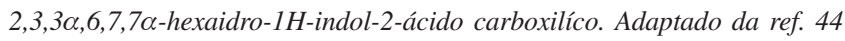

A reação do ${ }^{1} \mathrm{O}_{2}$ com resíduos de tirosina em peptídeos gera como produto principal um hidroperóxido no carbono $\mathrm{C}_{1}$, que, em baixas temperaturas, decai lentamente para seu álcool correspondente. A $37{ }^{\circ} \mathrm{C}$ e, particularmente, na presença de luz UV ou íons metálicos este hidroperóxido pode dar origem a oxi-radicais, que podem promover danos a outros alvos biológicos ${ }^{44}$.

\section{Reação com resíduos de histidina}

A oxidação de histidina livre pelo ${ }^{1} \mathrm{O}_{2}$ parece envolver a formação inicial de um ou mais endoperóxidos instáveis, através da 1,4 cicloadição do ${ }^{1} \mathrm{O}_{2}$ aos carbonos 2,4 e/ou 2,5 do anel imidazólico. 
Recentemente, evidências desta formação foram obtidas quando endoperóxidos de derivados imidazólicos foram identificados em temperaturas extremamente baixas ${ }^{45}$. Estes endoperóxidos sofrem rearranjo para um hidroperóxido. A decomposição deste hidroperóxido intermediário a um derivado carbonilado é seguida pela adição de uma molécula de água, produzindo uma imidazolona hidroxilada ${ }^{46}$. Os produtos finais desta oxidação incluem derivados do ácido aspártico, asparagina, uréia e outros produtos ainda não identificados ${ }^{47}$ (Esquema 3).

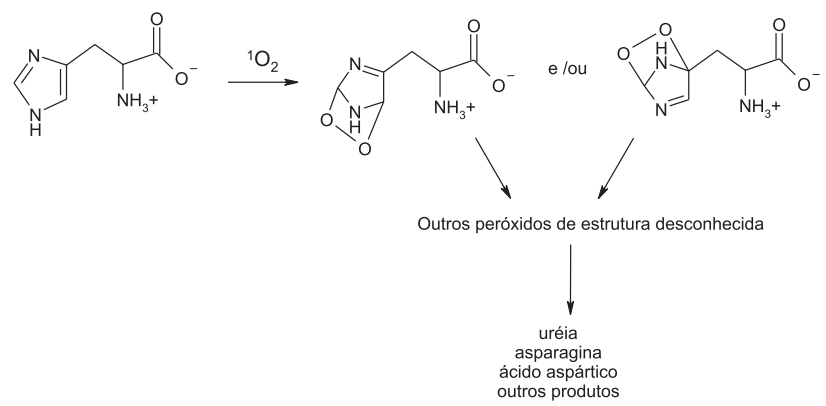

Esquema 3. Proposta do mecanismo de reação do ${ }^{1} \mathrm{O}_{2}$ com resíduos de histidina. Adaptado das refs. 46 e 47

\section{Reação com resíduos de metionina}

A fotooxidação de resíduos de metionina é dependente do $\mathrm{pH}$ : em $\mathrm{pH} \leq 6$, propõe-se que a oxidação ocorre via formação de uma espécie zwitterionica, que reage com uma segunda molécula de metionina resultando em duas moléculas de sulfóxido; com o aumento do $\mathrm{pH}$, outras reações podem concorrer: em $\mathrm{pH} \geq 9$ íons hidróxido podem levar a uma substituição no átomo de enxofre da espécie zwitterionica, resultando em um mol de peróxido de hidrogênio para cada mol de sulfóxido formado. Além dessas reações, quando $7 \leq \mathrm{pH} \leq 12$ também pode ser formado um intermediário cíclico estável, chamado deidrometionina, e um mol de peróxido de hidrogênio ${ }^{8,29,48}$.
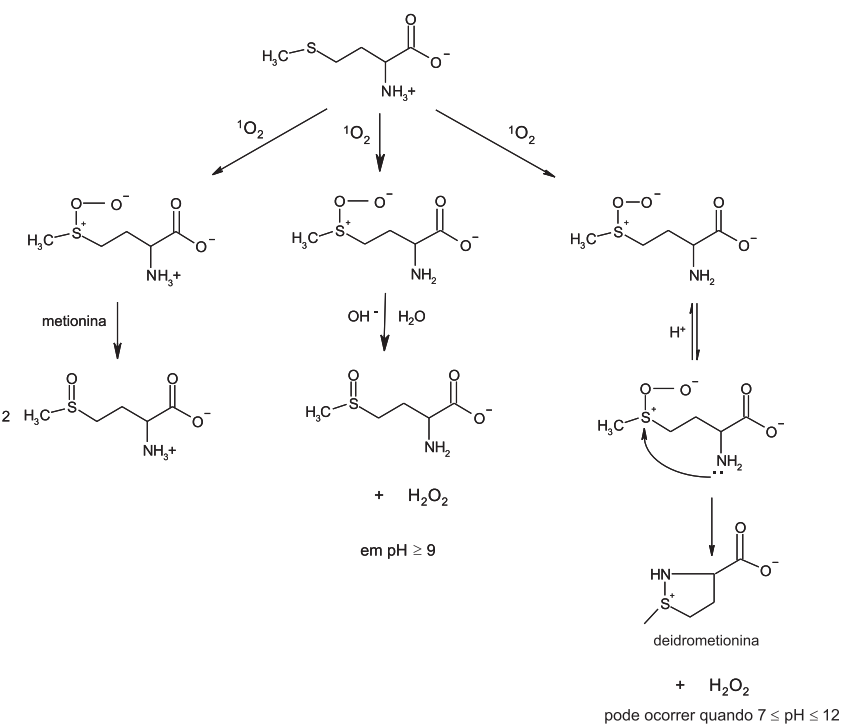

Esquema 4. Proposta do mecanismo de reação do ${ }^{1} \mathrm{O}_{2}$ com resíduos de metionina em diferentes pHs. Adaptado das refs. 8 e 29

\section{Reação com resíduos de cisteína}

Resíduos de cisteína livres reagem rapidamente com o ${ }^{1} \mathrm{O}_{2}$, produzindo o dissulfeto correspondente, de um modo não quantitativo. Além disso, oxiácidos como o ácido cistéico também podem ser formados em algumas condições. Outros produtos precisam ainda ser identificados. Em proteínas, espera-se que a razão entre a formação de dissulfeto e oxiácidos varie dependendo da estrutura da proteína, devido às barreiras estérica e eletrônica na formação do dímero $8,29,37$.

\section{Oxidação de proteínas pelo ${ }^{1} \mathrm{O}_{2}$}

Existem poucos trabalhos que estudam a oxidação de proteínas por ${ }^{1} \mathrm{O}_{2}$. Um destes trabalhos envolveu as ligações cruzadas de colágeno, existentes naturalmente na pele. Neste estudo, foi demonstrado que o ${ }^{1} \mathrm{O}_{2}$ oxida seletivamente os resíduos de histidina deste agregado protéico, podendo levar à destruição do mesmo, com formação de novas ligações cruzadas aberrantes e perturbação da função do colágeno na derme ${ }^{46}$. Em outro estudo, foi demonstrado que o ${ }^{1} \mathrm{O}_{2}$ pode reagir com proteínas do cristalino do olho, resultando em modificação estrutural que pode ser importante no desenvolvimento de catarata ${ }^{49}$. Da mesma forma, peróxidos protéicos têm sido detectados em células expostas ao ${ }^{1} \mathrm{O}_{2}$ gerado por fotossensibilização. Pesquisas evidenciaram que estes peróxidos têm remoção reduzida por enzimas celulares, tais como, catalase, peroxidase de raiz forte e $\mathrm{Cu} / \mathrm{Zn}$ superóxido dismutase, sendo que apenas tióis e ácido ascórbico são efetivos em removê-los ${ }^{50}$. Estes peróxidos protéicos podem reagir com outras biomoléculas, gerando um dano adicional. Por exemplo, já foi demonstrado que peróxidos protéicos foram capazes de causar a inibição de enzimas ${ }^{51,52}$ e induzir danos ao DNA ${ }^{53}$.

\section{Propagação do dano e conseqüências biológicas da oxidação de proteínas}

Os hidroperóxidos de proteínas gerados a partir do ${ }^{1} \mathrm{O}_{2}$ podem sofrer decomposição térmica ou catalisada por íons metálicos, gerando radicais peroxila ${ }^{54}$ (Equação 4)

$\mathrm{ROOH}+\mathrm{Fe}^{3+} \rightarrow \mathrm{ROO}^{\bullet}+\mathrm{Fe}^{2+}+\mathrm{H}^{+}$

Os hidroperóxidos de proteínas também podem sofrer redução por um elétron, gerando radicais alcoxila (reação de Fenton) ${ }^{54}$ (Equação 5)

$\mathrm{ROOH}+\mathrm{Fe}^{2+} \rightarrow \mathrm{RO}^{-}+\mathrm{HO}^{-}+\mathrm{Fe}^{3+}$

Deste modo, a formação de peróxidos em uma proteína a partir do ${ }^{1} \mathrm{O}_{2}$ pode resultar em danos subseqüentes a outras proteínas. Estes danos incluem inativação enzimática, como a que foi demonstrada quando caspases, cisteíno-proteases que desempenham um papel central na apoptose, foram expostas a hidroperóxidos de triptofano e tirosina ${ }^{55}$. Outro exemplo de inativação enzimática é o da enzima gliceraldeído 3-fosfato desidrogenase. Peróxidos de proteínas demonstraram reagir com o grupo tiol do sítio ativo desta enzima, inativando-a ${ }^{51}$. Por sua vez, a oxidação da lisozima pelo ${ }^{1} \mathrm{O}_{2}$ gerado por fotossensibilização causou a inativação parcial desta enzima ${ }^{52}$.

A remoção de $\mathrm{H}_{2} \mathrm{O}_{2}$ das células pela catalase é de vital importância, já que este peróxido pode dar origem a espécies mais reativas, tais como ${ }^{1} \mathrm{O}_{2}$ e radical hidroxila $\left({ }^{\circ} \mathrm{OH}\right)$. Vários estudos mostraram que a oxidação da catalase pelo ${ }^{1} \mathrm{O}_{2}$ gera espécies enzimáticas com pontos isoelétricos mais ácidos ${ }^{56-58}$. Esta oxidação foi detectada inclusive em um estudo com a catalase em cultura de células humanas ${ }^{59}$. A modificação parece ocorrer no grupo heme da enzima. A presença deste grupo heme modificado foi sugerida como indicadora da geração de ${ }^{1} \mathrm{O}_{2}$ in vivo. Contrastando com as modificações causadas ao grupo heme da catalase, verificou-se que o ${ }^{1} \mathrm{O}_{2}$ 
promove a oxidação de resíduos de metionina e tirosina do citocromo c. O citocromo c é uma hemeproteína mitocondrial fundamental no processo respiratório. Esta hemeproteína também é envolvida na cascata apoptótica, pois a liberação do citocromo c da mitocôndria para o citosol promove a ativação das caspases, desencadeando a apoptose celular. Contudo, os efeitos desta oxidação na apoptose celular ainda precisam ser detalhados ${ }^{60}$.

Outra consequiência da produção de peróxidos derivados de proteínas é a formação de ligações cruzadas e agregados protéicos, que podem resultar de reações secundárias independentes da produção contínua de ${ }^{1} \mathrm{O}_{2}$. Dentro deste contexto, cabe ressaltar a importância da formação de derivados oxidados do triptofano, em especial $\mathrm{N}$ formilquinurenina e quinurenina. É bem conhecido que o acúmulo gradual de quinureninas nos tecidos humanos pode resultar em um aumento do dano por fotossensibilização, já que estes compostos são agentes fotossensibilizantes eficientes. Este ponto é particularmente significante em órgãos humanos expostos à radiação solar ${ }^{41}$. Como exemplo, pode-se citar o cristalino do olho humano, que desempenha um papel fundamental na visão. O cristalino contém compostos de baixo peso molecular (formados principalmente de quinureninas) que atuam como filtros intra-oculares, absorvendo a luz UV na região situada entre 300 - $400 \mathrm{~nm}$, e prevenindo o dano induzido à retina por esta luz. Muitos pesquisadores têm investigado a possibilidade de estes filtros modificarem covalentemente o cristalino. Em pessoas jovens, as moléculas de filtros UV existem primariamente na forma livre. Entretanto, com o passar do tempo, o nível de quinureninas ligadas covalentemente às proteínas do cristalino do olho aumenta exponencialmente ${ }^{61}$. Parker e colaboradores ${ }^{62}$ demonstraram que a fotoexposição de agregados quinurenina-proteína pode iniciar um dano oxidativo mediado pelo ${ }^{1} \mathrm{O}_{2}$ às proteínas do cristalino do olho. Esta foto-oxidação resulta em formação de $\mathrm{H}_{2} \mathrm{O}_{2}$ e outros peróxidos protéicos. Também foi evidenciada a formação de produtos de oxidação de tirosina, tais como DOPA e ditirosina, neste processo. Não é claro o mecanismo pelo qual estes produtos são formados, contudo, é possível que estas reações ocorram via decomposição dos peróxidos iniciais a espécies reativas que, posteriormente, oxidariam resíduos de tirosina.

Oxidantes em geral produzem modificações em proteínas levando à perda de função e aumentando a taxa de degradação destas proteínas oxidadas. A via do proteossomo ubiquitina-26S é o principal mecanismo pelo qual células eucarióticas marcam proteínas para degradação ${ }^{63}$. Uma oxidação moderada das proteínas aumenta sua suscetibilidade à proteólise e as torna substrato para o proteossomo. Contudo, proteínas severamente oxidadas parecem ser substratos de difícil ubiquitinação, primeiro agregando-se e então formando ligações cruzadas que as tornam altamente resistentes à proteólise. A incapacidade de degradar proteínas extensivamente oxidadas pode contribuir para o acúmulo de agregados protéicos que ocorre em algumas doenças e durante o processo de envelhecimento ${ }^{64}$.

Uma importante consequiência biológica da oxidação de proteínas é a oxidação posterior do DNA pelos peróxidos formados. Peróxidos de triptofano e tirosina gerados por fotossensibilização com um agente intercalante de DNA são capazes de clivá-lo em experimentos realizados com plasmídio ${ }^{65}$. A oxidação do DNA também já foi demonstrada com peróxidos de histonas gerados por radiação gama. Desta forma, a geração inicial de peróxidos nas proteínas nucleares, tais como as histonas, pode promover um dano subseqüiente ao DNA, incluindo ligações cruzadas DNA-proteína e mutações ${ }^{53}$.

\section{Estratégias para análise e detecção do ${ }^{1} \mathrm{O}_{2}$ e de moléculas por ele oxidadas}

Para avaliar possíveis danos a biomoléculas, causados pelo ${ }^{1} \mathrm{O}_{2}$ e por moléculas por ele oxidadas, faz-se necessária à utilização de ferramentas analíticas, tais como seqüestradores químicos do ${ }^{1} \mathrm{O}_{2}$, termólise de endoperóxidos como fonte de ${ }^{1} \mathrm{O}_{2}$ e marcação isotópica de produtos. Seqüestradores químicos de ${ }^{1} \mathrm{O}_{2}$ são moléculas que reagem com o ${ }^{1} \mathrm{O}_{2}$ gerado e o produto pode então ser identificado. Por ex., pode-se utilizar a reação de ${ }^{1} \mathrm{O}_{2}$ com o 9,10-difenilantraceno (DPA $)^{66}$ ou com derivados de antraceno solúveis em água, como o 9,10-dietilantraceno disulfonato (EAS) ${ }^{11,67}$ (Esquema 5). Ambas as reações formam endoperóxidos estáveis, que podem ser detectados por HPLC ou outras técnicas. A termólise de endoperóxidos é outro exemplo importante, desenvolvido com o objetivo de se obter "fontes limpas" de ${ }^{1} \mathrm{O}_{2}$, compatíveis com as condições presentes em meios biológicos (meio aquoso, $\mathrm{pH}$ neutro, temperaturas moderadas). Merece destaque a decomposição térmica de endoperóxidos hidrossolúveis de derivados de naftaleno, a qual não gera subprodutos, não necessita de condições drásticas de trabalho e produz ${ }^{1} \mathrm{O}_{2}$ em uma velocidade e quantidade conhecidas ${ }^{68}$. Exemplos destes endoperóxidos incluem o endoperóxido do 3,3'-(1,4naftilideno)dipropanoato de sódio $\left(\mathrm{NDPO}_{2}\right)$ e o endoperóxido da $N, N^{\prime}$-di(2,3-diidroxipropil)-3,3'-(1,4-naftilideno)dipropanamida $\left(\mathrm{DHPNO}_{2}\right)^{67,69}$ (Esquema 6). A utilização do isótopo $\left[{ }^{18} \mathrm{O}\right]$ do oxigênio também é de particular interesse, já que desta forma é possível demonstrar como o ${ }^{1} \mathrm{O}_{2}$ ou seus produtos de oxidação podem reagir com alvos biológicos. Os produtos de oxidação que contêm o oxigênio marcado podem ser detectados usando-se métodos adequados, tais como HPLC acoplado à espectrometria de massas.

Recentemente, a marcação isotópica de hidroperóxidos de lipídios com $\left[{ }^{18} \mathrm{O}\right]$ foi utilizada a fim de esclarecer o mecanismo da geração de ${ }^{1} \mathrm{O}_{2}$ a partir destes hidroperóxidos. Neste mesmo traba-

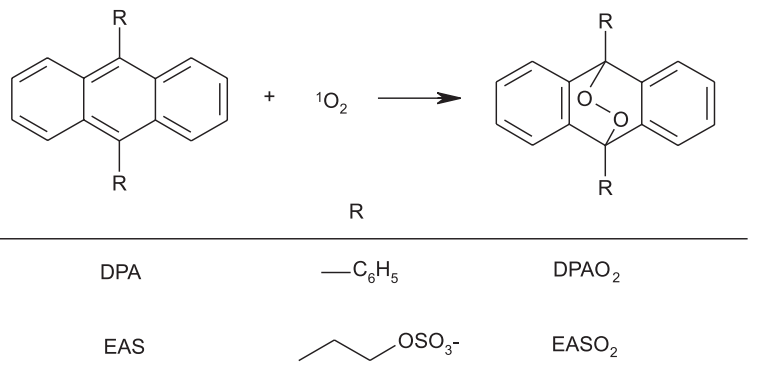

Esquema 5. Reação do ${ }^{1} \mathrm{O}_{2}$ com seus captadores. 9,10-difenilantraceno (DPA) e 9,10-dietilantraceno disulfonato (EAS), gerando os respectivos endoperóxidos $\left(\mathrm{DPAO}_{2}\right.$ e $\left.\mathrm{EASO}_{2}\right)$. Adaptado das refs. 11, 66 e 67

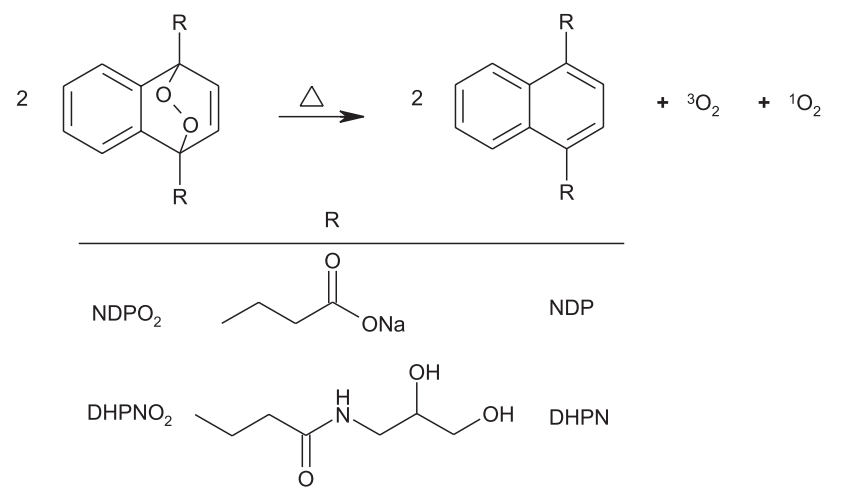

Esquema 6. Liberação do ${ }^{1} \mathrm{O}_{2}$ pela termólise do endoperóxido do 3,3'-(1,4naftilideno)dipropanoato de sódio $\left(\mathrm{NDPO}_{2}\right)$ e do endoperóxido da $N, N^{\prime}$ di(2,3-diidroxipropil)-3,3'-(1,4-naftilideno)dipropanamida ( $\left.\mathrm{HPNO}_{2}\right)$, gerando os respectivos derivados de naftaleno (NDP e DHPN). Adaptado das refs. 67-69 
lho, utilizou-se o DPA para seqüestrar o $\left[{ }^{18}\left({ }^{1} \mathrm{O}_{2}\right)\right]$ gerado. $\mathrm{O}$ DPA ${ }^{18} \mathrm{O}^{18} \mathrm{O}$ detectado por HPLC acoplado ao espectrômetro de massas constituiu uma prova inequívoca da geração de ${ }^{1} \mathrm{O}_{2}$ a partir de hidroperóxidos de lipídios ${ }^{24,70,71}$. De modo similar, o endoperóxido $\mathrm{DHPNO}_{2}$ marcado com $\left[{ }^{18} \mathrm{O}\right]{ }^{72}$ foi utilizado para evidenciar que o ${ }^{1} \mathrm{O}_{2}$, quando liberado em células, é capaz de oxidar diretamente o DNA celular. A reação foi demonstrada através da detecção de 8-oxo-7,8-diidro-2'-deoxiguanosina, um produto de oxidação do DNA, isotopicamente marcado com $\left[{ }^{18} \mathrm{O}\right]$ por HPLC acoplado ao espectrômetro de massas ${ }^{73}$.

Contrastando com pesquisas envolvendo lipídios e DNA, existem poucos estudos descrevendo as interações de ${ }^{1} \mathrm{O}_{2}$ com proteínas e as consequiências biológicas destas interações. As interações de hidroperóxidos de proteínas previamente formados pela reação com ${ }^{1} \mathrm{O}_{2}$ e alvos biológicos também precisam ser esclarecidas. As estratégias de análise e detecção de produtos estáveis, tais como as acima descritas para lipídios e DNA, podem ser de grande utilidade na elucidação do destino celular de proteínas oxidadas.

O estudo do papel dos produtos de oxidação de proteínas pelo ${ }^{1} \mathrm{O}_{2}$ e outros oxidantes em sistemas biológicos pode levar a respostas importantes sobre as implicações destas espécies nos processos celulares, uma vez que já começam a surgir evidências da participação destas espécies na indução de dano ao DNA e nos processos de sinalização celular.

\section{AGRADECIMENTOS}

À Fundação de Amparo a Pesquisa do Estado de São Paulo (FAPESP), ao Conselho Nacional de Desenvolvimento Científico e Tecnológico (CNPq) e ao Programa de Apoio aos Núcleos de Excelência (PRONEX/FINEP). P. D. Mascio e G. E. Ronsein são bolsistas da John Simon Guggenheim Memorial Foundation e da FAPESP, respectivamente.

\section{REFERÊNCIAS}

1. Hallliwell, B.; Gutteridge, J. M. C.; Free Radicals in Biology and Medicine, Oxford, 1999.

2. Khan, A.; Kasha, M.; J. Chem. Phys. 1963, 39, 2105.

3. Boveris, A.; Cadenas, E.; Chance, B.; Fed. Proc. 1981, 40, 195.

4. Browne, R.; Ogryzlo, E.; P. Chem. Soc. London 1964, 117.

5. Khan, A.; J. Am. Chem. Soc. 1981, 103, 6516.

6. Foote, C. S.; Science 1968, 162, 963.

7. Foote, C. S.; Photochem. Photobiol. 1991, 54, 659.

8. Straight, R. C.; Spikes, J. D. Em Singlet $\mathrm{O}_{2}$; Frimer, A. A., ed.; CRC Press: Boca Raton, 1985, vol. IV, p. 91.

9. Briviba, K.; Saha-Moller, C.; Adam, W.; Sies, H.; Biochem. Mol. Biol. Int. 1996, 38, 647.

10. Aubry, J. M. Em Membrane Lipid Oxidation; Vigo-Pelfrey, C., ed.; CRC Press, 1991, vol. II, p. 65.

11. Di Mascio, P.; Sies, H.; J. Am. Chem. Soc. 1989, 111, 2909.

12. Di Mascio, P.; Bechara, E.; Medeiros, M.; Briviba, K.; Sies, H.; FEBS Lett. 1994, 355, 287.

13. Martinez, G. R.; Di Mascio, P.; Bonini, M. G.; Augusto, O.; Briviba, K.; Sies, H.; Maurer, P.; Rothlisberger, U.; Herold, S.; Koppenol, W. H.; Proc. Natl. Acad. Sci. U. S. A. 2000, 97, 10307.

14. Held, A. M.; Halko, D. J.; Hurst, J. K.; J. Am. Chem. Soc. 1978, 100, 5732.

15. Kanofsky, J.; J. Biol. Chem. 1983, 258, 5991.

16. Kanofsky, J.; Wright, J.; Tauber, A.; FEBS Lett. 1985, 187, 299.

17. Kanofsky, J.; Wright, J.; Miles-Richardson, G.; Tauber, A.; J. Clin. Invest. 1984, 74, 1489.

18. Kanofsky, J.; J. Biol. Chem. 1984, 259, 5596.

19. Kanofsky, J.; J. Biol. Chem. 1988, 263, 14171.

20. Steinbeck, M.; Khan, A.; Karnovsky, M.; J. Biol. Chem. 1992, 267, 13425.

21. Kanofsky, J.; Sima, P.; J. Biol. Chem. 1991, 266, 9039.

22. Russell, G. A.; J. Am. Chem. Soc. 1957, 79, 3871.

23. Howard, J.; Ingold, K.; J. Am. Chem. Soc. 1968, 90, 1057.

24. Miyamoto, S.; Martinez, G.; Medeiros, M.; Di Mascio, P.; J. Am. Chem. Soc. 2003, 125, 6172 .
25. Bloodworth, A.; Eggelte, H. Em ref. 8, vol. II, p. 93.

26. Foote, C. S.; Denny, R. W.; J. Am. Chem. Soc. 1971, 93, 5162.

27. Baumstark, A.. Em ref. 8, vol. II, p. 1.

28. Foote, C. S.; Thomas, M.; Ching, T.-Y.; J. Photochem. 1976, 5, 172.

29. Ando, W.; Takata, T.. Em ref. 8, vol. III, p. 1.

30. Michaeli, A.; Feitelson, J.; Photochem. Photobiol. 1994, 59, 284.

31. Wilkinson, F.; Helman, W. P.; Ross, A. B.; J. Phys. Chem. Ref. Data 1995, $24,663$.

32. Monroe, B.. Em ref. 8, vol. I, p. 177.

33. Vever-Bizet, C.; Dellinger, M.; Brault, D.; Rougee, M.; Bensasson, R.; Photochem. Photobiol. 1989, 50, 321.

34. Prat, F.; Hou, C.-C.; Foote, C. S.; J. Am. Chem. Soc. 1997, 119, 5051.

35. Davies, M.; Biochem. Biophys. Res. Commun. 2003, 305, 761.

36. Matheson, I.; Etheridge, R.; Kratowich, N.; Lee, J.; Photochem. Photobiol. 1975, 21, 165.

37. Davies, M.; Photochem. Photobiol. Sci. 2004, 3, 17.

38. Nakagawa, M.; Yoshikawa, K.; Hino, T.; J. Am. Chem. Soc. 1975, 97, 6496.

39. Nakagawa, M.; Watanabe, H.; Kodato, S.; Okajima, H.; Hino, T.; Flippen, J. L.; Witkop, B.; Proc. Natl. Acad. Sci. U. S. A. 1977, 74, 4730.

40. Langlois, R.; Ali, H.; Brasseur, N.; Wagner, J.; van Lier, J.; Photochem. Photobiol. 1986, 44, 117.

41. Posadaz, A.; Biasutti, A.; Casale, C.; Sanz, J.; Amat-Guerri, F.; Garcia, N.; Photochem. Photobiol. 2004, 80, 132.

42. Jin, F.; Leitich, J.; von Sonntag, C.; J. Photochem. Photobiol., A 1995, 92, 147.

43. Criado, S.; Soltermann, A. T.; Marioli, J. M.; Garcia, N. A.; Photochem. Photobiol. 1998, 68, 453.

44. Wright, A.; Bubb, W. A.; Hawkins, C. L.; Davies, M. J.; Photochem. Photobiol. 2002, 76, 35.

45. Kang, P.; Foote, C. S.; Tetrahedron Lett. 2000, 41, 9623.

46. Au, V.; Madison, S.; Arch. Biochem. Biophys. 2000, 384, 133.

47. Tomita, M.; Irie, M.; Ukita, T.; Biochemistry 1969, 8, 5149.

48. Sysak, P.; Foote, C.; Ching, T.-Y.; Photochem. Photobiol. 1977, 26, 19.

49. Balasubramanian, D.; Du, X.; Zigler, J. S.; Photochem. Photobiol. 1990, 52,761 .

50. Morgan, P. E.; Dean, R. T.; Davies, M. J.; Free Radical Biol. Med. 2004, 36, 484.

51. Morgan, P. E.; Dean, R. T.; Davies, M. J.; Eur. J. Biochem. 2002, 269, 1916.

52. Silva, E.; De Landea, C.; Edwards, A.; Lissi, E.; J. Photochem. Photobiol., B 2000, 55, 196.

53. Luxford, C.; Morin, B.; Dean, R.; Davies, M.; Biochem. J. 1999, 344, 125.

54. Hawkins, C. L.; Davies, M. J.; Biochim. Biophys. Acta 2001, 1504, 196.

55. Hampton, M.; Morgan, P.; Davies, M. J.; FEBS Lett. 2002, 527, 289.

56. Lledias, F.; Rangel, P.; Hansberg, W.; J. Biol. Chem. 1998, 273, 10630.

57. Diaz, A.; Horjales, E.; Rudino-Pinera, E.; Arreola, R.; Hansberg, W.; J. Mol. Biol. 2004, 342, 971.

58. Lledias, F.; Rangel, P.; Hansberg, W.; Free Radical Biol. Med. 1999, 26 , 1396.

59. Lledias, F.; Hansberg, W.; Photochem. Photobiol. 1999, 70, 887.

60. Estevam, M. L.; Nascimento, O. R.; Baptista, M. S.; Di Mascio, P.; Prado, F. M.; Faljoni-Alario, A.; Zucchi, M. d. R.; Nantes, I. L.; J. Biol. Chem. 2004, 279, 39214.

61. Vazquez, S.; Aquilina, J. A.; Jamie, J. F.; Sheil, M. M.; Truscott, R. J. W.; J. Biol. Chem. 2002, 277, 4867.

62. Parker, N. R.; Jamie, J. F.; Davies, M. J.; Truscott, R. J. W.; Free Radical Biol. Med. 2004, 37, 1479.

63. Robinson, P. A.; Ardley, H. C.; J. Cell Sci. 2004, 117, 5191.

64. Grune, T.; Merker, K.; Sandig, G.; Davies, K. J. A.; Biochem. Biophys. Res. Commun. 2003, 305, 709.

65. Mahon, K.; Ortiz-Meoz, R.; Prestwich, E.; Kelley, S.; Chem. Commun. 2003, 15, 1956.

66. Turro, N. J.; Chow, M. F.; J. Am. Chem. Soc. 1981, 103, 7218.

67. Pierlot, C.; Aubry, J.; Briviba, K.; Sies, H.; Di Mascio, P.; Methods Enzymol. 2000, 319, 3.

68. Martinez, G. R.; Medeiros, M. H. G.; Di Mascio, P.; Quim. Nova 2000, 23, 686

69. Pierlot, C.; Hajjam, S.; Bathelemy, C.; Aubry, J.-M.; J. Photochem. Photobiol., B 1996, 36, 31.

70. Miyamoto, S.; Martinez, G.; Martins, A.; Medeiros, M.; Di Mascio, P.; J. Am. Chem. Soc. 2003, 125, 4510.

71. Miyamoto, S.; Martinez, G.; Martins, A.; Medeiros, M.; Di Mascio, P.; Biofactors 2004, 22, 333.

72. Martinez, G. R.; Ravanat, J.-L.; Medeiros, M. H. G.; Cadet, J.; Di Mascio, P.; J. Am. Chem. Soc. 2000, 122, 10212.

73. Ravanat, J.-L.; Di Mascio, P.; Martinez, G. R.; Medeiros, M. H. G.; Cadet, J.; J. Biol. Chem. 2000, 275, 40601. 